On Consuming Sacred Cows: Responses to Religious Value Violations

\author{
Kunalan Manokara \\ University of Amsterdam \\ Eva G. Krumhuber \\ University College London \\ Albert Lee* \\ Nanyang Technological University
}

\begin{abstract}
Author Notes
Correspondence concerning this article should be addressed to Albert Lee, School of Social Sciences, Nanyang Technological University, Singapore. E-mail: albertlee@ntu.edu.sg
\end{abstract}

Word count: 3320; 1 Figure

This manuscript has been submitted for peer review (Draft Version 2.0, as of 20/07/2020) 


\begin{abstract}
Animals have been a key part of religious rituals around the world for centuries. Whilst previous work has examined people's responses to norm violation in the context of animal slaughter for food, little is known about religious value violations regarding the consumption of animals deemed sacred. To fill this gap, we explore the mental processes that underlie judgments towards social others who consume such sacred animals. In a community sample of Hindus, we experimentally manipulated the type of meat consumed by fictitious targets using vignettes. Contrary to expectations, religiosity acted as a buffer against punishment intentions when observing religious value violations. Religiosity was negatively predictive of punishment intentions, only when the target was seen to be consuming a sacred animal (i.e. beef from cows). However, no significant effects were surfaced on measures of dehumanized perception, such that value violators would be viewed as animalistic and lacking restraint. Our findings contribute to the growing literature on religion, food consumption and social cognition, and point to potential caveats regarding when and why religious value violation may be deemed tolerable.
\end{abstract}

Keywords: religion, sacred animals, food choices, value violation, social cognition 


\section{On Consuming Sacred Cows: Responses to Religious Value Violations}

For centuries, animals have featured heavily in cultural and religious practices, albeit playing vastly different roles according to the rituals in question. Whilst the Mayans slaughtered animals to appease the gods (Steward, 1949), Indus Valley inhabitants worshipped particular animals as proxies of the gods (Kenoyer, 1991). Contemporary religious practices feature animals in equally diverse roles, with a common trend showing that people's perceptions of animals often go beyond their physical characteristics by inferring the underlying mental states (Loughnan, Bastian, \& Haslam, 2014). The attribution of mind to animals is a psychological process that is often intertwined with the moral status such animals deserve (Piazza et al., 2015). Both processes require sophisticated social cognition, whereby people rely on associative knowledge and culture-specific lay-theories (Kellert, 1984) to determine the extent of mind and moral concern an animal target deserves.

Whilst early work in psychology assessed people's affective and attitudinal responses towards animals (Rozin \& Fallon, 1980), scientific advances in the domain of social cognition (Gray, Gray, \& Wegner, 2007) point towards motivated processes in the perception and treatment of animals. This line of evidence has been mostly concerned with the distinction between pets, wild beasts, and livestock (Knight \& Herzog, 2009; Loughnan, Haslam, \& Bastian, 2010), as well as people's perception of animals in terms of warmth and competence (Sevillano \& Fiske, 2016) and intelligence (Piazza \& Loughnan, 2016). Most recently, the role of religion in shaping social perceptions has been evaluated, where animals deemed sacred by members of a faith were granted greater mental life than other creatures (Manokara, Lee, Kamble, \& Krumhuber, 2020). To further contribute to this literature on religion and animals, the present 
article explores peoples' reactions towards social others who consume such sacred animals for food.

\section{Violation of Religious Norms and Values}

A substantial body of literature has examined people's responses to norm violation in the context of animal slaughter for food. Most research points toward morality and disgust as the mechanisms via which meat avoidance is regulated (Grunert, 2006). For example, some animals are deemed unfit for consumption because the mere thought of slaughtering them elicits disgust amongst perceivers, as such actions would be intuitively immoral (Tybur, Lieberman, \& Griskevicius, 2009). Vegetarians express their attitudes towards meat eating in emotional rather than cognitive terms, where they deem animal slaughter to be disgusting and immoral (Rozin, Markwith, \& Stoess, 1997). An elaborate cross-cultural study on eating practices points towards the combined roles of disgust and morality in explaining the avoidance of taboo food items universally, regardless of whether such food was considered sacred or impure (Fessler \& Navarrete, 2003). The early theoretical suggestion of Rozin \& Fallon (1980), that disgust plays a critical role in the moralization of food avoidance behaviors, has been empirically validated with multiple studies thereafter (Chapman et al., 2009; Eskine, Kacinik, \& Prinz, 2011).

In comparison, little is known about the impact of religious value violation on perceivers, as much of the literature on intergroup relations focuses on social identity aspects that drive inter-religious tensions (Brown \& Hewstone, 2005). Religious value violations have mainly been studied within the context of homosexuality (Fulton, Gorsuch, \& Maynard, 1999) and atheism (Van den Bos, Van Ameijde, \& Van Gorp, 2006). For instance, Christian Americans have been found to hold greater prejudice towards homosexuals as compared to Americans from other religious backgrounds, and the value violating lifestyle of homosexuals mediated the effect of 
religiosity on negative attitudes (Rowatt et al., 2009). Similarly, atheists are perceived to be distrustful, especially by religious individuals, as the group is deemed to lack moral policing due to their disbelief in a higher power (Gervais, Shariff, \& Norenzayan, 2011). These studies posit a linear trend. In line with terror management theory, people react in defense of their worldview and reaffirm their religious commitments by negatively evaluating the violator (Greenberg, Solomon, \& Pyszczynski, 1997). Homosexuality and doubts about the existence of a higher power are the major taboos in many religions, as is the sacredness of animals (Bloom, 2012).

To this end, research is needed at the intersection of value violations pertaining to religion and food. Religion undoubtedly determines the consumption pattern of individuals by placing restrictions on people's eating habits and choices. Islam prohibits Muslims from eating meat that has not been slaughtered in line with religious conventions (Regenstein, Chaudry, \& Regenstein, 2003). On the other hand, Buddhism prescribes a vegetarian diet for its followers because the faith deems all living entities as equally deserving of kindness (Kaza, 2005). Given the plethora of real-world implications, it is important to empirically evaluate religious value violation in relation to eating practices, for both theoretical and applied purposes.

\section{Mind Attribution and Dehumanized Perception}

Mind attribution is a cognitive inference process grounded in the belief that the observed party possesses internal states that are reflective of the human mind (Waytz, Gray, Epley, \& Wegner, 2010). Existing theoretical frameworks conceptualize the human mind into distinct dimensions. Gray and colleagues (2012), for example, define mind perception in terms of agency and experience, such as the extent to which a target is perceived as capable of thoughts and emotions. In contrast, the Stereotype Content Model highlights the mental dimensions of competence and warmth. Prior work has shown that when a target is perceived as incompetent 
(e.g., unskilled) and unwarm (e.g., unkind), such target is perceived as lacking the capacity for sophisticated mental states and, thus, more likely to be dehumanized (Harris \& Fiske, 2006). The two-factor dehumanization model is another common explanation postulating that human beings constitute two sets of essential characteristics: uniquely human traits (such as civility that sets us apart from animals), and human nature traits (such as emotional responsiveness that distinguishes us from machines; Haslam et al., 2008).

Although each model has its own conceptual nuances and operational mechanisms, the underlying theoretical foundation is similar. Higher-order cognition and emotional complexity are deemed to be the signposts of humanness, and the perceived absence of these attributes is widely known as the antecedent of dehumanization (Haslam \& Stratemeyer, 2016). The denial of mental life is also used to justify inhumane actions (Haslam \& Loughnan, 2014), and dehumanized perception is the strongest form of prejudice, grounded in negative attitudes and beliefs concerning the target (Allport, 1954).

Dehumanization has been suggested as a response for value violation due to the moral implications attached to religious values (Bloom, 2012). As such, targets depicted to consume sacred animals should be deprived of mental life. In non-religious contexts, moral violators are deemed less human by perceivers (Brandt \& Reyna, 2011; Esses et al., 2008) and hence more likely to be punished (Maoz \& McCauley, 2008). Transgressing targets are often likened to wild animals (Bastian et al., 2011) that lack self-constraint and impulse-control (Haslam \& Loughnan, 2014). People who consume sacred animals should therefore be perceived as animalistic because their behavior reflects the "tooth-and-claw" norms of the animal kingdom where food consumption is driven purely by a need to survive and is not bounded by rationality or moral regulations (Saminaden, Loughnan, \& Haslam, 2010). Given the moral profanity associated with 
the consumption of sacred animals, transgressors should in turn be punished for their moral violations, and be perceived as having the mind of an animal for deciding to infringe sacredness in the first place.

\section{Present Research}

In this study, we explore the mental processes that underlie people's judgments towards social others who consume sacred animals. Namely, we examine Hindu participants' reactions when social others consume the meat of an animal that is deemed sacred: beef from cows. Participants were presented with fictitious profiles differing only on one attribute: what the described person was eating. Because our aim is to study people's perceptions of sacred animals, we recruited participants from a Hindu sample, a religion where animals feature heavily as a part of worship and religious mythology (Flood, 2008).

We hypothesize that people consuming sacred animals would be deprived of mental life and moral treatment by perceivers. Given that value violators are more likely to be evaluated negatively, we expect beef-eating social targets - reflective of religious transgressors - to be viewed as less human and more deserving of punishment than chicken-eating targets.

\section{Method}

\section{Participants}

A-priori power analysis using $\mathrm{G}^{*}$ Power (version 3.1.9; Faul, Erdfelder, Buchner, \& Lang, 2009) indicated that 70 participants would be sufficient to detect a medium-sized effect of condition (Cohen's $f=0.25$ ) with $80 \%$ statistical power (alpha $=.05, r=0.3$ ) in a mixed-design ANOVA. We intentionally oversampled to accommodate any necessary exclusion of participants who did not meet study requirements. A community sample of 74 participants (33 males, 41 females), with an age range between 18 and 42 years $(M=24.1, S D=6.06)$ completed the study 
in exchange for $\mathrm{S} \$ 4$. They were recruited from public areas in Singapore (i.e., shopping malls and cafés). All participants reported being non-vegetarian Hindus and had lived in Singapore for at least 10 years $(M=21.3, S D=6.07)$. Ethical approval was granted by a Department of Psychology in Singapore. Participants provided informed consent prior to participation.

\section{Materials}

Short text-based descriptions of three fictitious targets were created (for a similar procedure see Krumhuber, Tsankova \& Kappas, 2016); e.g. “My name is Zhong Hao, and I work for a finance company as an admin assistant. I enjoy playing soccer in my free time. In fact, it's part of my weekly routine to join my friends for a game every Sunday morning! I also enjoy classical music, which I listen to frequently over the radio or on my iPod." All characters were male, ethnically Chinese, employed in the finance sector, and enjoyed arts and sports.

Personality descriptions were combined with information about the character's food habits: (a) eating beef - a sacred animal: "I'm really passionate about café hopping, simply because I love to eat! I'm always on the lookout for eateries that serve beef burgers, a dish that I thoroughly enjoy. I don't even need fries on the side; it's the meat that I'm most interested in. Nothing beats the feeling of beef juice spilling out from a burger as you bite into it! When done right, the taste from tender beef is just exquisite."; (b) eating chicken - a commonly consumed animal: "I'm a real foodie, and I never give up the chance to sample new restaurants! My alltime favorite dish is a classic chicken chop. I believe that the quality of a restaurant can be judged from the way they cook their chicken. I prefer eating chicken chop without any sauces, just to feel the warm meat in my mouth. Crispy on the outside and chewy on the inside, that's the way I like it!"; or (c) no mention of eating was made: "Shopping malls often catch my attention, and I usually walk around aimlessly to enjoy the air-conditioning! Most of the time I only 
window-shop, unless I come across a product or item that is really worth its price. I spend most of my browsing time at outlets that sell electronics, but once in a while visit clothing stores too. Some of my favorite malls to hang out are located near Orchard Road."

We chose beef and chicken as the two food items of interest based on findings from past research (Flood, 2008; Manokara et al., 2020), suggesting that Hindus perceive cows to be more sacred than chickens.

\section{Procedure}

Participants responded to all three scenarios in a survey allegedly on marketing with an electronic tablet device using the Qualtrics survey software (Provo, UT). Target descriptions were presented individually and differed merely in terms of the character's food habits: a beefeating target (religious transgression), a chicken-eating target (neutral cultural norm), and a noneating target (buffer). The buffer condition always appeared in-between the beef and chicken conditions, whose order of presentation was counterbalanced. This was done to allow for a buffer in case of spill-over effects, where being exposed to a transgressor may potentially skew participants' evaluations of subsequent targets.

For each profile description, participants first rated the described target on 6 items measuring the extent to which the target was capable of the following human characteristics (Gray, Gray \& Wegner, 2007): pain, fear, pleasure, self-control, morality, and memory. A composite score of dehumanized perception was calculated by averaging across all six items, with lower scores indicative of stronger dehumanization $\left(\alpha_{\text {beef }}=.78 ; \alpha_{\text {chicken }}=.75 ; \alpha_{\text {buffer }}=.73\right)$. Three dummy items were added to mask the true purpose of the scale: appreciating art, driving safely, and playing sports. All 9 items were presented on the same screen and in a randomized 
order. A 7-point Likert-type scale was utilized for each item, anchored at $1=$ strongly disagree and 7 = strongly agree.

Next, participants were asked to allocate candies of two flavours to the described character: chocolate or bitter gourd. Pre-testing with a separate group of non-vegetarian Hindus $\left(N=17, M_{\text {age }}=28.5\right.$ years $)$ had shown that among nine candy flavours bitter gourd was rated (1 $=$ not at all, $7=$ very $m u c h)$ the most unpleasant $(M=1.76, S D=1.09)$, most suitable for a person who was disliked $(M=2.82, S D=1.52)$, and most befitting for someone who deserved to be punished $(M=2.76, S D=1.30)$. In contrast, chocolate flavour was deemed most pleasant $(M$ $=6.53, S D=0.72)$, most suitable for a person who was liked $(M=6.41, S D=1.06)$, and most befitting for someone who deserved to be rewarded $(M=5.65, S D=1.41)$. In the present study, participants' preference for gifting either of the two flavours was measured with a candy allocation task. Participants decided on a distribution of flavours that was deemed suitable for the described character, with selections compulsorily totalling 20 candies. The overall number of bitter gourd candies selected was used as an index of punishment intention (for a similar paradigm, see Lieberman et al., 1999).

Finally, religiosity was measured with four items, reflecting both intrinsic religiosity (“how much do you pray?" and "to what extent would you consider yourself a religiously devoted person?", anchored at $1=$ not at all, 7 = very much) and extrinsic religiosity ("how often do you visit places of worship?" and "how often do you participate in religious ceremonies?", anchored at $1=$ never, $7=$ very often $)$. The scale was highly reliable $(\alpha=.95)$.

\section{Results}

Separate mixed design analyses of variance (ANOVAs) were conducted for each outcome, where Condition (beef vs. chicken vs. buffer) was entered as a categorical within- 
subjects factor and Presentation Order (beef then chicken vs. chicken then beef) was input as a binary between-subjects factor, with Religiosity modelled as a continuous predictor.

For dehumanized perception, the effect of Condition failed to reach significance, $F(2,142)=1.08, p=.343, \eta_{\mathrm{p}}{ }^{2}=.015$. Neither the main effect of Presentation $\operatorname{Order}(F(1,71)=$ $\left.0.429, p=.515, \eta_{\mathrm{p}}{ }^{2}=.006\right)$ nor the main effect of Religiosity $\left(F(1,71)=0.298, p=.587, \eta_{\mathrm{p}}{ }^{2}=\right.$ .004) was found to be significant. The interaction terms between Condition and Presentation $\operatorname{Order}\left(F(2,142)=0.645, p=.526, \eta_{\mathrm{p}}{ }^{2}=.009\right)$ as well as Condition and Religiosity $(F(2,142)=$ $\left.0.390, p=.678, \eta_{\mathrm{p}}{ }^{2}=.005\right)$ were also non-significant. Our manipulation did not seem to influence dehumanized perception, and religiosity was not predictive of dehumanization either.

For punishment intentions, the main effects of Condition $\left(F(2,142)=2.41, p=.094, \eta_{\mathrm{p}}{ }^{2}=\right.$ $.033)$, Presentation Order $\left(F(1,71)=0.512, p=.477, \eta_{\mathrm{p}}{ }^{2}=.007\right)$, and Religiosity $(F(1,71)=2.72$, $\left.p=.104, \eta_{\mathrm{p}}^{2}=.037\right)$ were all non-significant. The interaction term between Condition and Presentation Order failed to reach significance as well, $F(2,142)=1.27, p=.285, \eta_{\mathrm{p}}{ }^{2}=.018$. However, the interaction effect between Condition and Religiosity was found to be marginally significant, $F(2,142)=2.89, p=.059, \eta_{\mathrm{p}}{ }^{2}=.039$. We hence probed this term further, by conducting simple slopes analyses via correlations between religiosity and punishment intentions within each condition. Religiosity was negatively associated with punishment intentions only in the beef-eating condition $(r=-.30, p=.011,95 \% \mathrm{CI}=-.49,-.07)$, but not in the chicken-eating condition $(r=-.16, p=.182,95 \% \mathrm{CI}=-.37, .07)$ or in the buffer condition $(r=.03, p=.802$, $95 \% \mathrm{CI}=-.20, .26)$. The more religious Hindus rated themselves to be, the less likely they were to punish transgressing targets who consumed sacred animals (see Figure 1). 

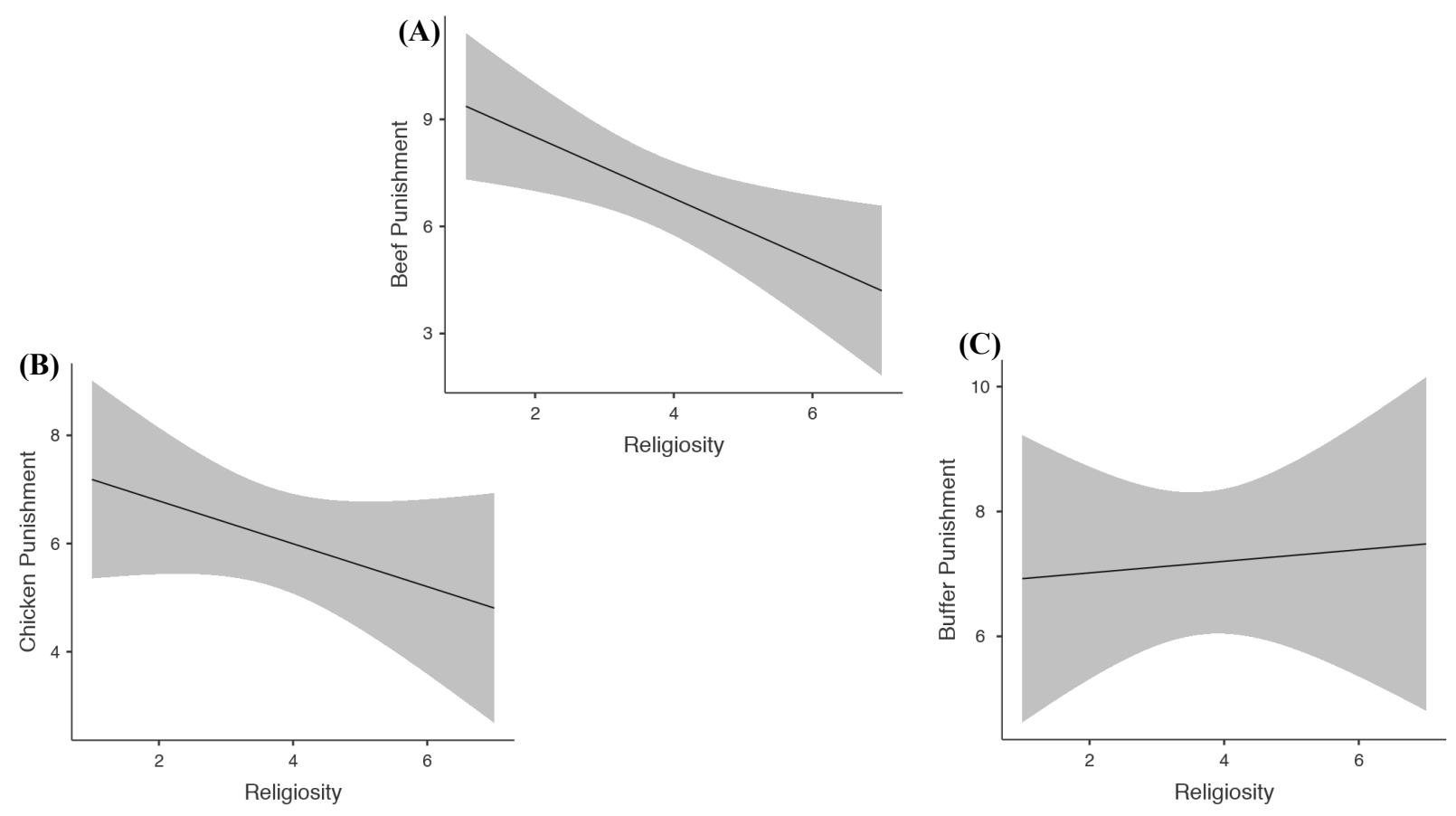

Figure 1. Negative association between religiosity and punishment intentions only in the beef eating condition $(\mathrm{A})$, but not in the chicken eating condition $(\mathrm{B})$ or in the buffer condition $(\mathrm{C})$

\section{Discussion}

Global concerns surrounding religious fundamentalism have invigorated research on religiosity, with value violation once again becoming a topic of public interest (Ramsay et al., 2014). The present research addressed this gap by examining the mental mechanisms that are engaged when sacred animals are consumed for food by social others. Religious transgressions did not elicit dehumanized perception. However contrary to expectations, religiosity acted as a buffer against punishment intentions when observing value violating food choices.

A potential reason for this finding could lie within the core tenets associated with liberal Hinduism, which preach benevolence and acceptance of other peoples' values (Klostermaier, 2007). It must also be noted that most work conducted in the past on religious value violations has been examined through the lens of Christianity (Fulton et al., 1999; Rowatt et al., 2009); a 
religious identity with very different guiding values deemed central. As such, our work adds a unique cross-cultural angle to the literature and points to a caveat in the context of existing findings.

Interestingly, our manipulations did not elicit self-reported dehumanized perception Three possible explanations could underpin those null findings. Firstly, the demographic features of the sample itself. Singaporeans are relatively tolerant of diversity and are well informed of other racial groups' cultural practices due to the multicultural makeup of the country (Goh, 2008). Given that beef eating is common for the Chinese population, knowledge of this group's practices could have mitigated desires to dehumanize and punish in the present study. Secondly, the insensitivity of the present mind perception measures should be questioned. While we operationalized dehumanization with words and labels reflective of mental states (Gray et al., 2007), perhaps items that reflect the tooth-and-claw nature of animalistic dehumanization (Haslam et al., 2008) would have been more appropriate for the current paradigm. Finally, the vignettes themselves could have elicited mental life by default, given that we described all targets to be engaging in cognitively sophisticated activities such as art appreciation.

Future research could evaluate the generalizability of the obtained findings by including Hindu samples from other national cultures and people from a different religious group. For instance, Muslims are inclined to perceive some animals as impure and unclean (e.g. pig; Regenstein, Chaudry, \& Regenstein, 2003), even though pork is commonly consumed in other cultures. It remains meaningful to examine the reactions to the consumption of impure animals across religious groups, which could lead to insights in the domains of mind perception, religiosity, and morality. 
In this context, it would also be interesting to investigate the emotional mechanisms that underpin animalism and punishing desires. Anger and disgust may play differential roles according to the type of religious transgression being observed, where anger arises in reaction to deliberate and planned violations (O’Mara et al., 2011) whilst disgust is elicited when one's own purity is threatened (Inbar \& Pizzaro, 2014). Religious affiliations of both the perceiver and the target are key to evaluating this phenomenon in the future.

In conclusion, the present research illustrates that while religiosity mitigates the effect of value violating food choices on punishment intentions, such effects only surface under very specific conditions. Furthermore, the psychological mechanisms that underpin such social judgments merit greater exploration. Our findings contribute to the emerging field of social cognition at the intersection of religion and food choices. 


\section{References}

Bastian, B., Laham, S. M., Wilson, S., Haslam, N., \& Koval, P. (2011). Blaming, praising, and protecting our humanity: The implications of everyday dehumanization for judgments of moral status. British Journal of Social Psychology, 50(3), 469-483.

Bloom, P. (2012). Religion, morality, evolution. Annual review of psychology, 63, 179-199.

Brandt, M. J., \& Reyna, C. (2011). The chain of being a hierarchy of morality. Perspectives on Psychological Science, 6(5), 428-446.

Brown, R., \& Hewstone, M. (2005). An integrative theory of intergroup contact. Advances in experimental social psychology, 37, 255-343.

Chapman, H. A., Kim, D. A., Susskind, J. M., \& Anderson, A. K. (2009). In bad taste: Evidence for the oral origins of moral disgust. Science, 323(5918), 1222-1226.

Eskine, K. J., Kacinik, N. A., \& Prinz, J. J. (2011). A bad taste in the mouth gustatory disgust influences moral judgment. Psychological Science, 22(3), 295-299.

Esses, V. M., Veenvliet, S., Hodson, G., \& Mihic, L. (2008). Justice, morality, and the dehumanization of refugees. Social Justice Research, 21(1), 4-25.

Faul, F., Erdfelder, E., Buchner, A., \& Lang, A. G. (2009). Statistical power analyses using G* Power 3.1: Tests for correlation and regression analyses. Behavior research methods, 41(4), 1149-1160.

Fessler, D. M., \& Navarrete, C. D. (2003). Meat is good to taboo: Dietary proscriptions as a product of the interaction of psychological mechanisms and social processes. Journal of Cognition and Culture, 3(1), 1-40.

Flood, G. (Ed.). (2008). The Blackwell Companion to Hinduism. New York, NY: John Wiley \& Sons. 
Fulton, A. S., Gorsuch, R. L., \& Maynard, E. A. (1999). Religious orientation, antihomosexual sentiment, and fundamentalism among Christians. Journal for the Scientific Study of Religion, 14-22.

Gervais, W. M., Shariff, A. F., \& Norenzayan, A. (2011). Do you believe in atheists? Distrust is central to anti-atheist prejudice. Journal of personality and social psychology, 101(6), 1189.

Goh, D. P. (2008). From colonial pluralism to postcolonial multiculturalism: Race, state formation and the question of cultural diversity in Malaysia and Singapore. Sociology Compass, 2(1), 232-252.

Gray, H. M., Gray, K., \& Wegner, D. M. (2007). Dimensions of mind perception. Science, 315(5812), 619-619.

Gray, K., Young, L., \& Waytz, A. (2012). Mind perception is the essence of morality. Psychological Inquiry, 23(2), 101-124.

Greenberg, J., Solomon, S., \& Pyszczynski, T. (1997). Terror management theory of self-esteem and cultural worldviews: Empirical assessments and conceptual refinements. Advances in experimental social psychology, 29, 61-139.

Grunert, K. G. (2006). Future trends and consumer lifestyles with regard to meat consumption. Meat science, 74(1), 149-160.

Harris, L. T., \& Fiske, S. T. (2006). Dehumanizing the lowest of the low: Neuroimaging responses to extreme out-groups. Psychological science, 17(10), 847-853.

Haslam, N., Loughnan, S., Kashima, Y., \& Bain, P. (2008). Attributing and denying humanness to others. European review of social psychology, 19(1), 55-85. 
Haslam, N., \& Loughnan, S. (2014). Dehumanization and infrahumanization. Annual Review of Psychology, 65, 399-423.

Haslam, N., \& Stratemeyer, M. (2016). Recent research on dehumanization. Current Opinion in Psychology, 11, 25-29.

Inbar, Y. \& Pizarro, D. A. (2014). Pollution and purity in moral and political judgment. In J. C. Wright \& H. Sarkissian (Eds.), Advances in Experimental Moral Psychology: Affect, Character, and Commitments (pp. 111-129). New York, NY: Continuum Press.

Kaza, S. (2005). Western Buddhist motivations for vegetarianism. Worldviews: Global Religions, Culture, and Ecology, 9(3), 385-411.

Kellert, S. R. (1984). Urban American perceptions of animals and the natural environment. Urban ecology, 8(3), 209-228.

Kenoyer, J. M. (1991). The Indus valley tradition of Pakistan and western India. Journal of World Prehistory, 5(4), 331-385.

Klostermaier, K. K. (2007). A Survey of Hinduism. Albany, NY: State University of New York Press.

Knight, S., \& Herzog, H. (2009). All creatures great and small: New perspectives on psychology and human-animal interactions. Journal of Social Issues, 65(3), 451-461.

Krumhuber, E. G., Tsankova, E., \& Kappas, A. (2016). Examining subjective and physiological responses to norm violation using text-based vignettes. International Journal of Psychology.

Lieberman, J. D., Solomon, S., Greenberg, J., \& McGregor, H. A. (1999). A hot new way to measure aggression: Hot sauce allocation. Aggressive Behavior: Official Journal of the International Society for Research on Aggression, 25(5), 331-348. 
Loughnan, S., Haslam, N., \& Bastian, B. (2010). The role of meat consumption in the denial of moral status and mind to meat animals. Appetite, 55(1), 156-159.

Loughnan, S., Bastian, B., \& Haslam, N. (2014). The psychology of eating animals. Current Directions in Psychological Science, 23(2), 104-108.

Manokara, K., Lee, A., Kamble, S. V., Dr., \& Krumhuber, E. (2020, July 7). Mind your Meat: Religious Differences in the Social Perception of Animals. Retrieved from osf.io/qgyn4

Maoz, I., \& McCauley, C. (2008). Threat, dehumanization, and support for retaliatory aggressive policies in asymmetric conflict. Journal of Conflict Resolution, 52(1), 93-116.

O'Mara, E. M., Jackson, L. E., Batson, C. D., \& Gaertner, L. (2011). Will moral outrage stand up?: Distinguishing among emotional reactions to a moral violation. European Journal of Social Psychology, 41(2), 173-179.

Piazza, J., \& Loughnan, S. (2016). When meat gets personal, animals' minds matter less: Motivated use of intelligence information in judgments of moral standing. Social Psychological and Personality Science, 7(8), 867-874.

Piazza, J., Ruby, M. B., Loughnan, S., Luong, M., Kulik, J., Watkins, H. M., \& Seigerman, M. (2015). Rationalizing meat consumption. The 4Ns. Appetite, 91, 114-128.

Ramsay, J. E., Pang, J. S., Shen, M. J., \& Rowatt, W. C. (2014). Rethinking value violation: Priming religion increases prejudice in Singaporean Christians and Buddhists. International Journal for the Psychology of Religion, 24(1), 1-15.

Regenstein, J. M., Chaudry, M. M., \& Regenstein, C. E. (2003). The kosher and halal food laws. Comprehensive reviews in food science and food safety, 2(3), 111-127. 
Rowatt, W. C., LaBouff, J., Johnson, M., Froese, P., \& Tsang, J. A. (2009). Associations among religiousness, social attitudes, and prejudice in a national random sample of American adults. Psychology of Religion and Spirituality, 1(1), 14.

Rozin, P., \& Fallon, A. (1980). The psychological categorization of foods and non-foods: A preliminary taxonomy of food rejections. Appetite, 1(3), 193-201.

Rozin, P., Markwith, M., \& Stoess, C. (1997). Moralization and becoming a vegetarian: The transformation of preferences into values and the recruitment of disgust. Psychological Science, 8(2), 67-73.

Saminaden, A., Loughnan, S., \& Haslam, N. (2010). Afterimages of savages: Implicit associations between primitives, animals and children. British Journal of Social Psychology, 49(1), 91-105.

Sevillano, V., \& Fiske, S. T. (2016). Warmth and competence in animals. Journal of Applied Social Psychology, 46(5), 276-293.

Steward, J. H. (1949). Cultural causality and law: a trial formulation of the development of early civilizations. American Anthropologist, 51(1), 1-27. doi:10.1525/aa.1949.51.1.02a00020

Tybur, J. M., Lieberman, D., \& Griskevicius, V. (2009). Microbes, mating, and morality: individual differences in three functional domains of disgust. Journal of personality and social psychology, 97(1), 103.

Waytz, A., Gray, K., Epley, N., \& Wegner, D. M. (2010). Causes and consequences of mind perception. Trends in Cognitive Sciences, 14(8), 383-388.

Van den Bos, K., Van Ameijde, J., \& Van Gorp, H. (2006). On the psychology of religion: The role of personal uncertainty in religious worldview defense. Basic and Applied Social Psychology, 28(4), 333-341. 